\title{
Visually augmented targeted combination light therapy for acne vulgaris: a case report
}

\author{
Alireza Yazdi ${ }^{1} \mathbb{B}$, Colin-William Lyons ${ }^{1 *}$ and Niamh Roberts ${ }^{2}$
}

\begin{abstract}
Background: Acne vulgaris is a common skin disease. Pharmacological modalities for treatment are proven to be efficacious but have limitations. Light therapy for acne vulgaris has shown promise in previous studies. This case report and its accompanying images show how a novel approach of visually augmented high fluence light therapy has been used to good effect.

Case presentation: A 26-year-old Caucasian woman with acne vulgaris resistant to treatment with topical therapy underwent three sessions of combination potassium titanyl phosphate laser $(532 \mathrm{~nm}) /$ heodymium-doped: yttrium aluminum garnet laser $(1064 \mathrm{~nm}$ ) light therapy with visually augmented narrow spot size and high fluence. A 73\% reduction in total inflammatory lesions was evident 6 months after the initial treatment.

Conclusions: This case report illustrates that there may be utility in this novel approach of narrow spot size, magnification-assisted, high fluence targeted combination laser therapy for inflammatory acne.
\end{abstract}

Keywords: Acne vulgaris, Phototherapy, Light therapy, Dermatology

\section{Background}

Acne vulgaris is a common skin disease affecting $90 \%$ of people at some time in their lives, to varying degrees. It can have a profound psychological impact on the patient, often out of proportion from the perceived physical effect.

Established medical treatment for acne includes topical application of benzoyl peroxide, topical and oral antibiotics, and systemic retinoids for severe or resistant acne. Although proven to be efficacious, these treatments have disadvantages that limit their use. Systemic retinoids are teratogenic and have systemic side effects, while non-compliance is an issue with topical treatment. There is also the problem of growing antibiotic resistance of the Cutibacterium acnes organism that contributes to inflammation in acne [1].

There has been recent interest in the role of light therapy in acne. A recent Cochrane review concluded that high quality evidence was lacking, but that treatment

\footnotetext{
* Correspondence: Colin-william.Lyons@imperial.ac.uk

${ }^{1}$ Department of Primary Care and Public Health, Faculty of Public Health,

Imperial College London, London, UK

Full list of author information is available at the end of the article
}

with green light was more effective than placebo [2]. There have been a number of promising results from studies on a range of energy-based devices [3].

The following case illustrates an approach to using phototherapy for acne that uses a novel combination of narrow spot size wavelengths with high energy level phototherapy under visual magnification to achieve a 73\% reduction in inflammatory lesions. A literature search of acne phototherapy indicates that this is a unique approach that merits further investigation.

\section{Case presentation}

A 26-year-old Caucasian woman with Fitzpatrick skin type II presented with facial acne vulgaris. She had a slim build, no evidence of hirsutism, and no significant past medical or family history. Multiple inflammatory lesions (37 in total), predominantly papules, were present bilaterally, consistent with severe (grade 4) acne on the US Food and Drug Administration (FDA) Investigator's Global Assessment (IGA) scale for acne severity [4] (Fig. 1). There was evidence of baseline atrophic boxcar scarring. Previous treatment for her acne consisted of a course of topical Duac (benzoyl peroxide and 


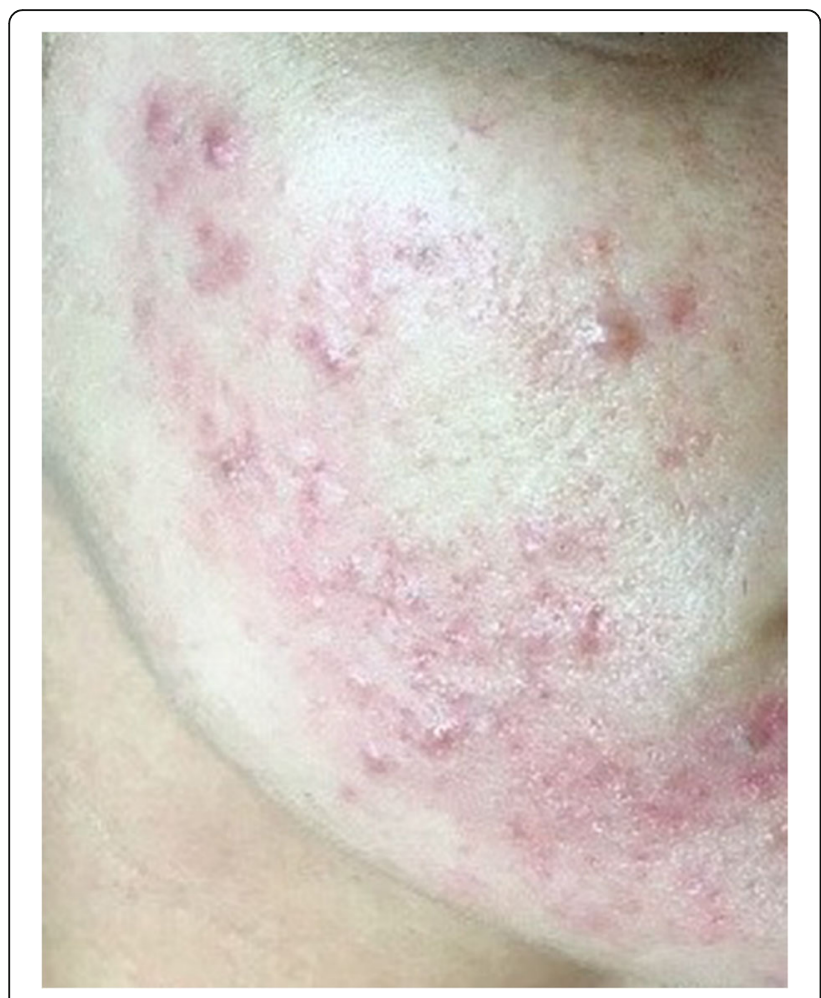

Fig. 1 Baseline, prior to first treatment

clindamycin) and microdermabrasion, both of which had limited effect. Retinoid therapy was contraindicated due to her family planning considerations.

Three treatments in total of combination nonablative laser therapy were applied; each session was held 2 to 3 weeks apart. We used a combination of treatment with high fluence potassium titanyl phosphate (KTP) and neodymium-doped: yttrium aluminum garnet (Nd:YAG) laser.

KTP laser settings of $532 \mathrm{~nm}$, high fluence $20 \mathrm{~J} / \mathrm{cm}^{2}$, 20 millisecond pulse width, $1 \mathrm{~mm}^{2}$ spot size, and $2 \mathrm{~Hz}$ pulse rate were used superficially, targeting the oxyhemoglobin within the pilosebaceous unit. Nd:YAG laser settings of $1064 \mathrm{~nm}, 150$ to $250 \mathrm{~J} / \mathrm{cm}^{2}, 55$ to 75 millisecond pulse width, and $1 \mathrm{~mm}^{2}$ spot size were used to eradicate the base of a hair follicle on a deeper level of the dermis along with any des-oxyhemoglobin resulting from the more superficial treatment. No topical sensitizer was used. Polarized visual magnification with a $5 \times$ headset magnification was used to assist with identification of lesions. External sclera shields were applied to our patient during treatment.

The procedure was painless. On each occasion following treatment, erythema of the treated area was apparent for approximately 3 days but subsided uneventfully with no blistering. There were no late complications. A $73 \%$ reduction in total inflammatory lesions (from 37 to 10) was evident on completion of the three applications when our patient was reviewed 6 months after the initial treatment (Fig. 2). This represented a reduction in acne severity from severe (grade 4) to mild (grade 2) on the IGA scale. Photos were taken with iPhone 5 camera $8 \mathrm{MP}$ with illumination via a Lifemax High Vision light without flash. Atrophic boxcar scarring, which was evident prior to the treatment, remained. She reported that she was very satisfied with the outcome of the treatment.

\section{Discussion}

The method of phototherapy used in this case aims to precisely target the infected pilosebaceous unit with a narrow spot size green laser using visual augmentation, thus limiting damage to adjacent tissue. An infrared laser is used to target melanin in a deeper layer and resolve the mottled appearance of des-oxyhemoglobin following superficial treatment.

Studies on the use of green light (495 to $570 \mathrm{~nm}$ ) in the treatment of acne have treated the entire surface of the designated treatment side, or with a notably larger spot size, no visual augmentation, and lower fluence. Baugh and Kucaba demonstrated efficacy with $12 \mathrm{~J} / \mathrm{cm}^{2}$ fluence treatment of the entire surface of the designated treatment side [5]. Yilmaz et al. used 5 to $12 \mathrm{~J} / \mathrm{cm}^{2}$

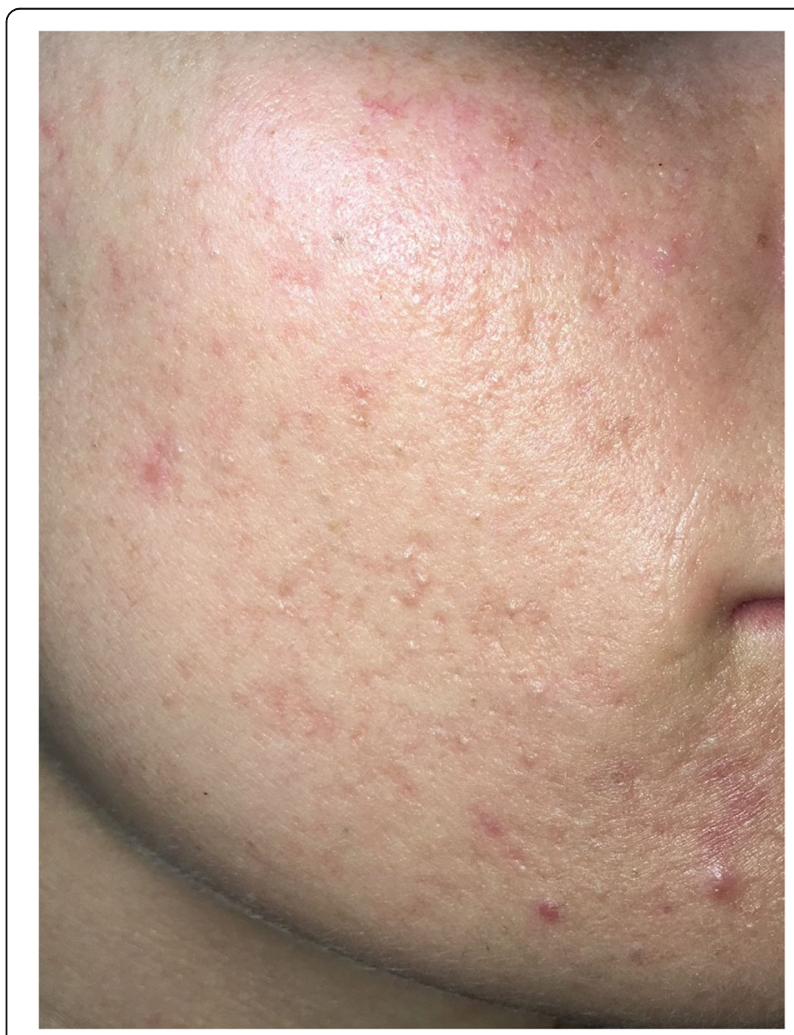

Fig. 2 Six months after first treatment 
fluence with a $4 \mathrm{~mm}$ spot size. Neither used magnification aid [6].

Combination laser therapy of different wavelengths of the green and infrared spectrum have been shown to be safe and effective in pulsed dye lasers (PDL) [7] with a postulated synergistic mechanism of action accounting for increased efficacy versus monophasic treatment. A literature search found no comparable studies for the $\mathrm{KTP} / \mathrm{Nd}$ :YAG combination used in this case.

This case study represents a unique instance of combination KTP laser (532 nm)/Nd:YAG laser (1064 nm) light therapy with visually augmented narrow spot size and high fluence. The outcome of this case indicates that this treatment method is a candidate for further research.

\section{Conclusions}

Optimal parameters in phototherapy for acne are yet to be established. This case illustrates that there may be utility in this novel approach of narrow spot size and magnificationassisted targeted combination laser therapy for inflammatory acne that merits further investigation.

\section{Acknowledgements}

Imperial College London is grateful for support from the NW London NIHR Collaboration for Leadership in Applied Health Research \& Care.

\section{Funding}

None.

\section{Availability of data and materials}

The images supporting the conclusion of this case report are included within the article. Additional images used to calculate the total reduction of inflammatory papules available on request.

\section{Authors' contributions}

$\mathrm{CL}$ managed the patient and performed the follow-up. AY wrote the initial manuscript, with revision and major contributions from $\mathrm{CL}$ and NR. All authors read and approved the final manuscript.

\section{Ethics approval and consent to participate}

Not applicable.

\section{Consent for publication}

Written informed consent was obtained from the patient for publication of this case report and any accompanying images. A copy of the written consent is available for review by the Editor-in-Chief of this journal.

\section{Competing interests}

$\mathrm{CL}$ is the medical director of a laser clinic limited company.

\section{Publisher's Note}

Springer Nature remains neutral with regard to jurisdictional claims in published maps and institutional affiliations.

\section{Author details}

'Department of Primary Care and Public Health, Faculty of Public Health, Imperial College London, London, UK. Gordano School, Portishead, Bristol, UK.
Received: 15 May 2017 Accepted: 20 September 2017

Published online: 31 October 2017

References

1. Coates P, Vyakrnam S, Eady EA, Jones CE, Cove JH, Cunliffe WJ. Prevalence of antibiotic-resistant propionibacteria on the skin of acne patients: 10-year surveillance data and snapshot distribution study. Br J Dermatol. 2002;146:840-8.

2. Barbaric J, Abbott R, Posadzki P, et al. Light therapies for acne: abridged Cochrane systematic review including GRADE assessments. Br J Dermatol. 2017. doi:10.1111/bjd.15495.

3. Handler MZ, Bloom BS, Goldberg DJ. Energy-Based Devices in Treatment of Acne Vulgaris. Dermatol Surg. 2016:42:573-85.

4. Draft Guidance for Industry - Acne Vulgaris: Developing Drugs for Treatment. Rockville: United States Food and Drug Administration; 2005.

5. Baugh WP, Kucaba WD. Nonablative Phototherapy for Acne Vulgaris Using the KTP 532 nm Laser. Dermatol Surg. 2005;31:1290-6.

6. Yilmaz O, Senturk N, Yuksel EP, et al. Evaluation of 532-nm KTP laser treatment efficacy on acne vulgaris with once and twice weekly applications. J Cosmet Laser Ther. 2011;13:303-7.

7. Jung JY, Choi YS, Yoon MY, Min SU, Suh DH. Comparison of a Pulsed Dye Laser and a Combined 585/1,064-nm Laser in the Treatment of Acne Vulgaris. Dermatol Surg. 2009;35:1181-7.
Submit your next manuscript to BioMed Central and we will help you at every step:

- We accept pre-submission inquiries

- Our selector tool helps you to find the most relevant journal

- We provide round the clock customer support

- Convenient online submission

- Thorough peer review

- Inclusion in PubMed and all major indexing services

- Maximum visibility for your research

Submit your manuscript at www.biomedcentral.com/submit
) Biomed Central 